Original Article

\title{
COMPARATIVE STUDY OF LIPID PROFILE IN PATIENTS OF NON-DIABETIC CHRONIC KIDNEY DISEASE IN RELATION TO ITS SEVERITY
}

\author{
BIBHU PRASAD BEHERA
}

Department of Internal Medicine, Saheed Laxman Nayak Medical College and Hospital, Koraput, Odisha, India

Email: drbibhu1111@yahoo.com

Received: 08 May 2020, Revised and Accepted: 10 Jun 2020

\begin{abstract}
Objective: Chronic Kidney Disease (CKD) is a silent epidemic of the $21^{\text {st }}$ century. Cardiovascular disease (CVD) is a major cause of morbidity and mortality among patients with CKD. This study aims to evaluate the type of dyslipidemia in CKD patients and correlates with the severity of renal dysfunction in CKD patients.
\end{abstract}

Methods: The observational study was conducted in the Department of General Medicine, PRM MCH, Baripada between May 2018 and January 2019. 262 patients of CKD above $15 \mathrm{y}$ of age, satisfying the inclusion and exclusion criteria were included in the study.

Results: Out of 262 patients, 64.50\% (169) were male and 35.50\% (93) were females with M: F of 1.8:1. The age range was from 20 to 95. The average age of the patients in the study was $56.66+12.22 \mathrm{y} .45 .04 \%$ (118) of the patients were between 46 and $60 \mathrm{y}$ of age. $68.70 \%$ of the patients had dyslipidemia. The comparison between lipid profiles of cases and controls showed a significant increase in total cholesterol, triglyceride, LDL and decrease in HDL.

Conclusion: The prevalence of dyslipidemia in non-diabetic CKD is high. A high degree of abnormality is found in HDL with disease progression, which is statistically significant. Therefore, maintenance of desired lipid levels either through diet or early initiation of lipid-lowering drugs can be helpful in decreasing the risk of cardiovascular complications in CKD patients.

Keywords: Chronic kidney disease, Dyslipidemia, Total cholesterol, Triglyceride, High-density lipoprotein

(C) 2020 The Authors. Published by Innovare Academic Sciences Pvt Ltd. This is an open access article under the CC BY license (http://creativecommons.org/licenses/by/4.0/) DOI: http://dx.doi.org/10.22159/ijpps.2020v12i8.38221. Journal homepage: https://innovareacademics.in/journals/index.php/ijpps.

\section{INTRODUCTION}

Chronic kidney disease (CKD) encompasses a spectrum of different pathophysiologic processes associated with abnormal kidney function and a progressive decline in glomerular filtration rate (GFR) [1]. CKD is a clinical syndrome due to irreversible kidney dysfunction leading to excretory, metabolic and synthetic failure culminating into the accumulation of non-protein nitrogenous substances and presenting with various clinical manifestations [2]

Chronic Kidney Disease (CKD) is a silent epidemic of the 21st century. Its occurrence is universal, not confined to the developed countries only. Globally, CKD is the 12th cause of death and the 17th cause of disability, respectively [3]. Estimated from population data, about $6 \%$ of the adult populations in the US have CKD stage 1 and 2 , and $4.5 \%$ have CKD stage 3 and 4 [1].

It has been estimated that the age-adjusted incidence rate of EndStage Renal Disease (ESRD) in India is around 229 per million population1, and more than one lakh new patients enter renal replacement programs annually in India [4]. It is estimated that the number of cases of kidney failure will increase disproportionately in developing countries, such as China and India, where the number of elderly people is increasing [5]. "Screening and Early Evaluation of Kidney Disease" (SEEK), a community-based voluntary health screening program started in India in 2006 with tests serum creatinine and urine analysis, reported a very high prevalence of $17.4 \%$ of CKD using an abbreviated modified diet in renal disease (MDRD) formula, a glomerular filtration (GFR) estimation formula [3]. As per the database of CKD registry of India, the yearly incidence of ESRD in India is approximately $150-200 \mathrm{pmp}$ and DM is an important cause of CKD in approximately $30-40 \%$ of the patients [6]. The prevalence of ESRD and patients on RRT has increased over the last two decades [7].

It is well acknowledged that cardiovascular disease (CVD) is a major cause of morbidity and mortality among patients with CKD [1, 8] Major outcomes of CKD include the progression of CKD to end-stage renal disease with increased risk for development of cardiovascular disease [9]. Most of the patients with CKD die from cardiovascular system complications before ever reaching Stage 5 CKD [1]

Even mild chronic renal dysfunction contributes actively to the development of CVD, so the American Heart Association has recommended that these patients should be classified in the highest risk group for developing cardiovascular events.

Patients with CKD are subjected to accelerated atherosclerosis leading to increased cardiovascular complications. Patients with CKD have a reduction in the activity of lipoprotein lipase and hepatic triglyceride lipase. This interferes with the uptake of triglyceriderich, apolipoprotein B containing lipoproteins by the liver and in peripheral tissue, yielding increased circulation of these atherogenic lipoproteins [10]. Disturbances in lipoprotein metabolism are evident even in the early stages of CKD and usually follow a downhill course that parallels the deterioration in renal function [11]. Severe lipid metabolism disorders arise in patients with kidney failure and the lipid metabolism disorder peculiar to this patient group is known as uremic dyslipidemia [11], which may accelerate its progression [12]. Abnormal lipid profile in CKD includes hypertriglyceridemia, increase in triglyceride remnant Lp (a) increase in very-low-density lipoprotein (VLDL), decrease in high density lipoprotein (HDL), total cholesterol (TC) and low-density lipoprotein (LDL) usually within normal limits except in nephrotic syndrome patients [13]. Dyslipidemia is a major risk factor for coronary heart disease $[14,15]$; it has prompted interest in the identification and management of abnormalities in plasma lipids and lipoproteins.

Experimental studies suggest that hyperlipidemia accelerates renal damage due to progressive glomerulosclerosis and tubulointerstitial disease [16]. There is also growing evidence that abnormalities in lipid metabolism may contribute to renal disease progression [17] Lipid-lowering treatment can reduce renal damage and preserve renal function [18]. The triglyceride-rich apoB containing 
lipoproteins are found to be associated with accelerated deterioration of renal function [15]; however, the pathophysiological mechanism is not fully understood. Use of lipidlowering agents may be helpful in correcting the lipid abnormalities, but a proper clinical trial is needed to establish the efficacy of hypolipidemic drugs on the attenuation of lipid abnormalities and to prevent the progression of renal disease [19].

We encounter a large number of patients with CKD with abnormal serum lipid profiles in our institution of Pandit Raghunath Murmu Medical College and Hospital, Baripada. As these being unpublished data we want to conduct a study, first of this type in our new college, to evaluate the type of dyslipidemia in CKD patients and correlates with the severity of renal dysfunction in CKD patients; which may have a future prognostic and management implication in patients with CKD.

\section{MATERIALS AND METHODS}

The observational study was conducted in the Department of General Medicine, PRM MCH, Baripada. The patients of CKD who had attended to department of general medicine OPD and who were admitted to department of general medicine, PRM MCH, Baripada between May 2018 and January 2019 were taken in our study.

\section{Inclusion criteria}

- All patients of CKD above $15 \mathrm{y}$ of age satisfying the following criteria were included in the study. Criteria for diagnosis of CKD were as given by-National Kidney Foundation: K/DOQI clinical practice guidelines for Chronic Kidney Disease: Evaluation, Classification and Stratification [20].

CKD is defined as the presence, for at least $3 \mathrm{mo}$, of evidence of kidney damage with an abnormal GFR or alternatively, by a GFR $<60$ $\mathrm{ml} / \mathrm{min} / 1.73 \mathrm{~m}^{2}$ BSA [20].

Kidney damage is evidenced by-

- Proteinuria $>300 \mathrm{mg} /$ day OR

- Pathological abnormality found in histopathological study OR

- Renal imaging study (USG) showing bilateral contracted kidneys $<9 \quad \mathrm{~cm}$ with thinned parenchyma and reduced corticomedullary differentiation.

\section{Exclusion criteria}

- Patients aged below $15 \mathrm{y}$ of age

- Patients on haemodialysis

- Patients with diabetes mellitus, hypothyroid, liver disease, Coronary heart disease

- Patients on lipid-lowering drugs

- Kidney transplanted patients

262 CKD patients were included in the study. All patients diagnosed with moderate to severe CKD, e-GFR was calculated according to the CKD-EPI (Chronic Kidney Disease Epidemiology Collaboration) equation, 2009 and divided into two groups. e-GFR was graded G1, G2, G3a, G3b, G4 and G5 as per the KDIGO 2012 guidelines [1]. 20 healthy persons were taken as controls (Group A). Group B $\rightarrow$ Patients with e-GFR $>30 \mathrm{ml} / \mathrm{min}$ was considered as moderate CKD (Stage 3) $(\mathrm{n}=55))$. Group $\mathrm{C} \rightarrow$ Patients with e-GFR $<30 \mathrm{ml} / \mathrm{min}$ was considered as severe CKD (Stage 4 and 5) $(n=207))$.

\section{Investigations}

All patients had undergone thorough clinical examination and laboratory investigations like complete blood counts, serum urea and creatinine, blood sugar and lipid profile. Ultrasound of the abdomen was done on every patient. A fasting serum lipid profile included serum cholesterol, triglyceride, HDL and LDL cholesterol on a Fully Automated analyzer (Erba EM360).

\section{Statistical analysis}

The statistical analysis was done using the Statistical Package for Social Sciences (SPSS) version 21.0. Univariate analysis was used in the description of demographic characteristics of the study population. Discrete variables were presented as frequency and percentages. Continuous variables were presented as means and standard deviation (SD) for unpaired data; the Student t-test was used to compare mean values (for two groups). Pearson's correlation was used to determine the association between eGFR and other variables. Fisher's exact test was used to determine the significant associations between categorical variables. P-value $<0.05$ was considered statistically significant* and $<0.001$ was considered as statistically extremely significant**.

Lipid classification was done according to NCEP-ATP III Guidelines: Risk factor

Total cholesterol (mg/dl)

$<200$ Desirable

200-239 Borderline High

$>240$ High

Triglyceride (mg/dl)

$<150$ Normal

150-199 Borderline High

200-499 High

$>500$ Very High

HDL-C (mg/dl)

$<40$ Low

$>60$ High

LDL-C (mg/dl) Goal

$<100$ Optimal

100-129 Near or above optimal

130-159 Borderline High

160-189 High

>190 Very high

\section{RESULTS}

During the study period, 262 patients with CKD attended to MOPD and admitted in the medicine ward of PRM MCH, Baripada, fulfill inclusion and exclusion criteria. All the cases were studied for the clinical presentation, risk factors and laboratory parameters.

In our study, 262 patients with CKD were included; which constitutes $64.50 \%$ (169) of male and $35.50 \%$ (93) of females with M: F of 1.8:1; with age ranging from 20 to 95 . The average age of the patients in the study was $56.66+12.22 \mathrm{y}$. The average age of the male and female patients in the study was $56.16+12.63$ and $57.57+11.46$ $\mathrm{y}$, respectively.

Fig. 1 shows $45.04 \%$ (118) of the patients were between 46 and 60 $y$ of age, followed by $27.86 \%$ (73) of the patients were between 61 and $75 \mathrm{y}$ of age; the majority $(66.41 \%)$ being below $60 \mathrm{y}$ age group. $79.01 \%$ (207 cases) of the patients in our study group belong to stage 4 and stage 5 chronic kidney diseases. All the cases in 15-30 y of age group are severe CKD (stage 4 and 5).

In our study, we found that $32.82 \%$ CKD cases had hypertension. $30.18 \%$ of male CKD cases had hypertension and $37.63 \%$ female CKD cases had hypertension. The association between HTN and gender distribution is not statistically significant $(p=0.271)$ [table 1]. 


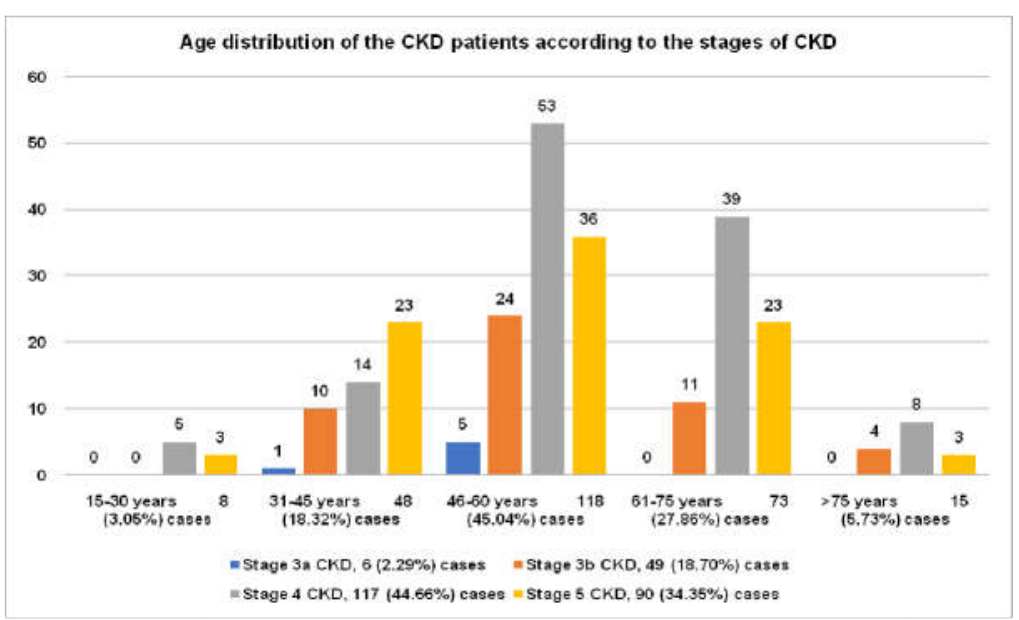

Fig. 1: Age distribution of the CKD patients according to the stages of CKD as per e-GFR

Table 1: Gender distribution with or without HTN

\begin{tabular}{|c|c|c|c|c|c|c|c|}
\hline & Male & f\% & female & f\% & total & f\% & p value \\
\hline CKD with HTN & 51 & $30.18 \%$ & 35 & $37.63 \%$ & 86 & $32.82 \%$ & $\mathrm{p}=0.271$ \\
\hline CKD without HTN & 118 & $69.82 \%$ & 58 & $62.37 \%$ & 176 & $67.18 \%$ & \\
\hline Total & 169 & $100 \%$ & 93 & $100 \%$ & 262 & $100 \%$ & \\
\hline
\end{tabular}

The association between HTN and gender distribution is not statistically significant $(\mathrm{p}=0.271)$.

The mean value of blood urea in study patients was $110.94 \pm 62.47$ $\mathrm{mg} / \mathrm{dl}$, with range from $25 \mathrm{mg} / \mathrm{dl}$ to $421 \mathrm{mg} / \mathrm{dl}$. The mean value of serum creatinine was $4.16 \pm 2.62 \mathrm{mg} / \mathrm{dl}$, with range from $1.5 \mathrm{mg} / \mathrm{dl}$ to $14.7 \mathrm{mg} / \mathrm{dl}$. $18.70 \%$ of CKD patients had a serum creatinine level $>6 \mathrm{mg} / \mathrm{dl}$.
$68.70 \%$ (180) of the patients in the study population had dyslipidemia with any one of the parameters. Only $20(7.63 \%)$ patients had both abnormal triglyceride and HDL levels. The prevalence of dyslipidemia among CKD patients with relation to the severity is statistically significant $\left(p=0.033^{*}\right)$ (table 2$)$.

Table 2: Incidence of dyslipidemia among CKD patients with relation to the severity

\begin{tabular}{lllllll}
\hline & Group-B & f\% & Group-C & f\% & total & f\% \\
\hline CKD with dyslipidemia & 31 & $56.36 \%$ & 149 & $71.98 \%$ & 180 & $68.70 \%$ \\
CKD without dyslipidemia & 24 & $43.64 \%$ & 58 & $28.02 \%$ & 82 & $31.30 \%$ \\
Total & 55 & $100 \%$ & 207 & $100 \%$ & 262 & $100 \%$ \\
\hline
\end{tabular}

The prevalence of dyslipidemia among CKD patients with relation to the severity is statistically significant $\left(p=0.033^{*}\right)$

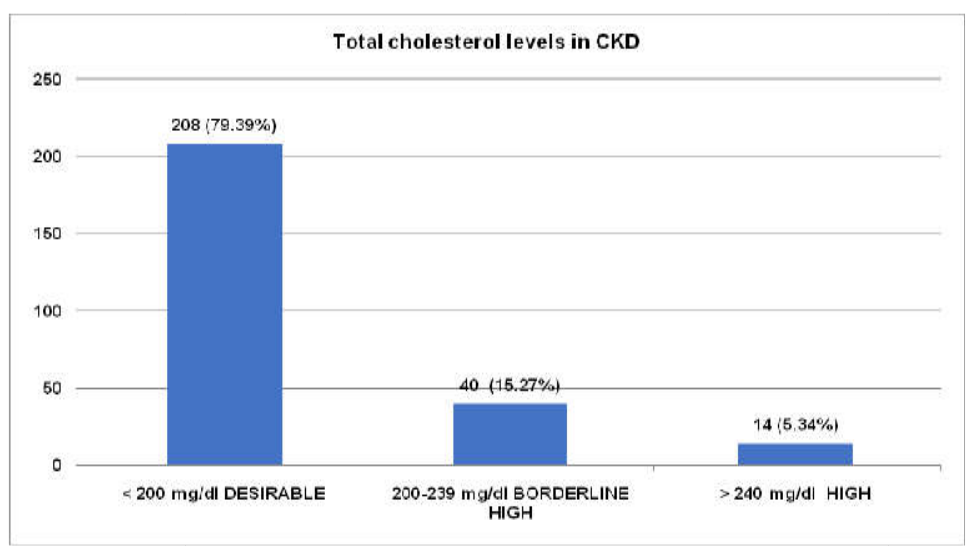

Fig. 2: Total cholesterol levels in CKD

The mean value of serum cholesterol was $164.04 \pm 47.85 \mathrm{mg} / \mathrm{dl}$, with range from $44 \mathrm{mg} / \mathrm{dl}$ to $323 \mathrm{mg} / \mathrm{dl} .19 .61 \%$ of the cases were having hypercholesterolemia [fig. 2].
The mean value of serum triglyceride was $147.16 \pm 69.40 \mathrm{mg} / \mathrm{dl}$, with a range from $41 \mathrm{mg} / \mathrm{dl}$ to $467 \mathrm{mg} / \mathrm{dl} .37 .40 \%$ of the cases were having hypertriglyceridemia [fig. 3]. 


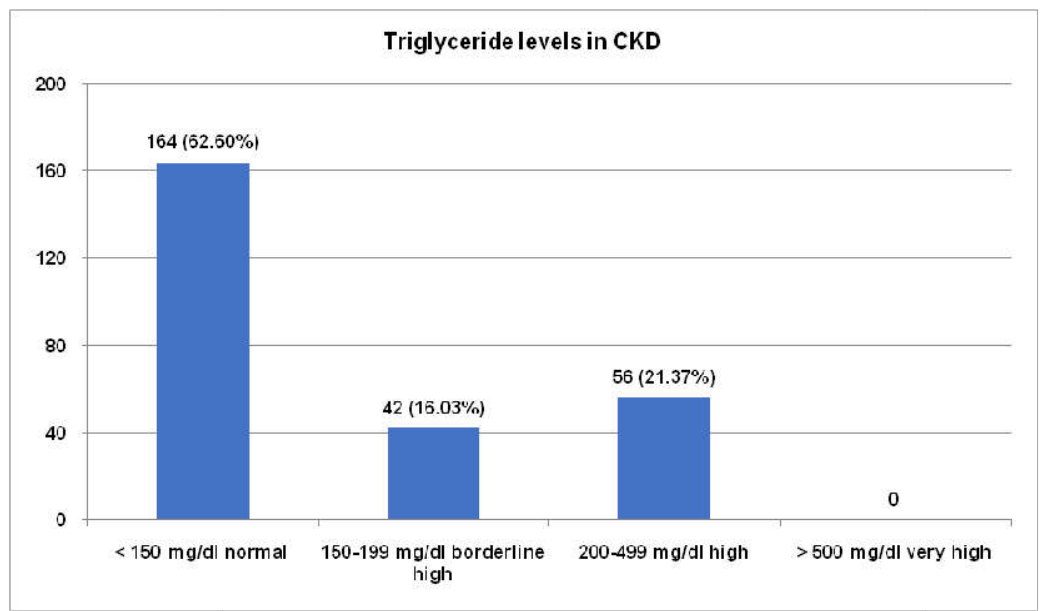

Fig. 3: Triglyceride levels in CKD

The mean value of serum HDL was $51.50 \pm 16.72 \mathrm{mg} / \mathrm{dl}$, with range from $4 \mathrm{mg} / \mathrm{dl}$ to $126 \mathrm{mg} / \mathrm{dl}$. $21.37 \%$ of the study group was having HDL level below $40 \mathrm{mg} / \mathrm{dl}$ [fig. 4]
The mean value of serum LDL was $91.41 \pm 31.24 \mathrm{mg} / \mathrm{dl}$, with range from $12 \mathrm{mg} / \mathrm{dl}$ to $203 \mathrm{mg} / \mathrm{dl}$. $11.07 \%$ of the study group was having an increased level of LDL [fig. 5].

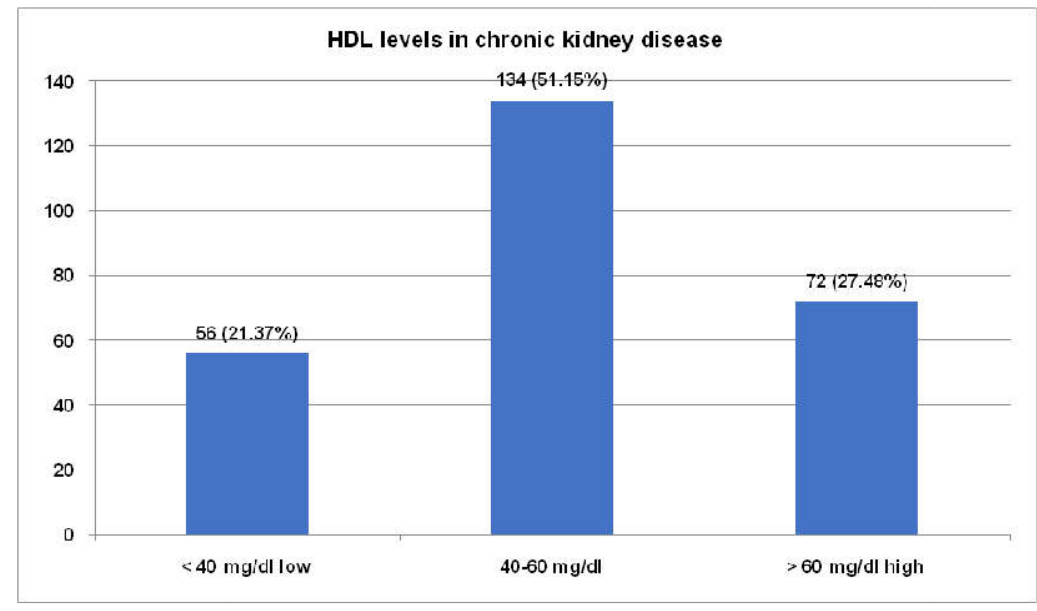

Fig. 4: HDL levels in chronic kidney disease

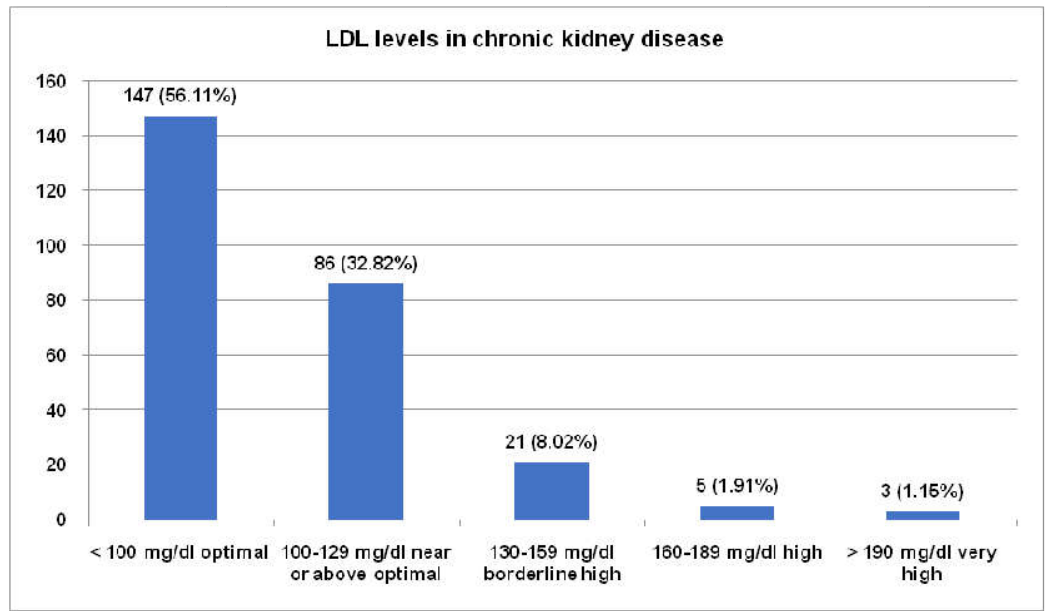

Fig. 5: LDL levels in chronic kidney disease 
Table 3 shows the correlation coefficient of eGFR with lipid profile parameters. Negative Pearson's correlation coefficient value indicates the level of triglyceride increase with the decline of GFR and positive Pearson's correlation coefficient value indicates the level of cholesterol, HDL, LDL decrease with the decline of GFR. On correlating e-GFR with various parameters, statistical significance was observed with HDL $(r=0.1962, p=$ $0.001^{* *}$ ).

Table 3: Correlation between e-GFR and lipid profile

\begin{tabular}{lcc}
\hline e-GFR vs. & Pearson's correlation (r) & Significance (p) \\
\hline Total cholesterol & 0.112 & 0.070 \\
Serum triglyceride & -0.0195 & 0.759 \\
HDL & 0.1962 & $0.001^{* *}$ \\
LDL & 0.10988 & 0.076 \\
\hline
\end{tabular}

On correlating with e-GFR, statistical significance was observed with HDL ( $\left.r=0.1962, \mathrm{p}=0.001^{* *}\right)$.

Table 4 shows the comparison between lipid profiles of cases and controls showed significant difference between total cholesterol $(\mathrm{p}=$ $\left.0.002^{*}\right)$, triglyceride $\left(p=0.002^{*}\right)$, HDL $\left(p=0.008^{*}\right)$, LDL $\left(p=0.013^{*}\right)$
On comparing various parameters between cases and controls, there is a significant rise in blood Urea $(\mathrm{p}<0.001)$ and serum Creatinine $(\mathrm{p}<0.001)$.

Table 4: Laboratory parameters of CKD patients and controls

\begin{tabular}{llll}
\hline Parameters & Controls (mean+SD) & CKD patients (mean+SD) & P-value \\
\cline { 2 - 3 } & $\mathbf{n = 2 0}$ & $\mathbf{n = 2 6 2}$ & \\
\hline Blood urea $(\mathrm{mg} / \mathrm{dl})$ & $28.50+12.63$ & $410.94+62.47$ & $<.16+2.62$ \\
Serum creatinine $(\mathrm{mg} / \mathrm{dl})$ & $1.03+0.17$ & $164.04+47.85$ & $<0.001^{* *}$ \\
Total cholesterol $(\mathrm{mg} / \mathrm{dl})$ & $130.25+23.32$ & $147.16+69.40$ & $0.002^{*}$ \\
Serum triglyceride $(\mathrm{mg} / \mathrm{dl})$ & $99.45+28.28$ & $51.50+16.72$ & $0.002^{*}$ \\
HDL $(\mathrm{mg} / \mathrm{dl})$ & $61.70+11.68$ & $94.41+31.24$ & $0.008^{*}$ \\
LDL $(\mathrm{mg} / \mathrm{dl})$ & $76.70+16.24$ & $0.013^{*}$ \\
\hline
\end{tabular}

Comparison between lipid profiles of cases and controls showed a statistically significant difference. Values are expressed as Mean + SD.

Table 5: Association of laboratory parameter with severity of CKD patients (e-GFR)

\begin{tabular}{|c|c|c|c|c|c|c|}
\hline Parameter & $\begin{array}{l}\text { Group } \\
\text { A/control } \\
\text { (mean+SD) }\end{array}$ & $\begin{array}{l}\text { Group B/moderate } \\
\text { CKD (e-GFR>30) } \\
(\text { mean+SD) }\end{array}$ & $\begin{array}{l}\text { Group C } \\
\text { /severe CKD } \\
(\text { e-GFR<30) } \\
(\text { mean+SD) } \\
\end{array}$ & $\begin{array}{l}\text { P-value (A vs. B) } \\
\text { control vs. } \\
\text { moderate CKD }\end{array}$ & $\begin{array}{l}\text { P-value (A vs. C) } \\
\text { control vs. } \\
\text { severe CKD }\end{array}$ & $\begin{array}{l}\text { P-value (B vs. C) } \\
\text { moderate CKD } \\
\text { vs. severe CKD }\end{array}$ \\
\hline & $\mathrm{n}=\mathbf{2 0}$ & $n=55$ & $\mathrm{n}=207$ & & & \\
\hline Age (years) & $41.05+17.75$ & $55.89+10.66$ & $56.86+12.62$ & $<0.001^{* *}$ & $<0.001^{* *}$ & 0.602 \\
\hline Systolic BP (mm Hg) & $118.30+5.28$ & $138.91+28.54$ & $135.61+30.20$ & $0.002^{*}$ & $0.001^{* *}$ & 0.468 \\
\hline Diastolic BP (mm Hg) & $75.40+4.21$ & $83.18+19.4$ & $81.50+16.11$ & 0.081 & 0.093 & 0.511 \\
\hline Blood urea $(\mathrm{mg} / \mathrm{dl})$ & $28.50+12.63$ & $54.31+19.20$ & $125.99+61.35$ & $<0.001^{* *}$ & $<0.001^{* *}$ & $<0.001^{* *}$ \\
\hline $\begin{array}{l}\text { Serum creatinine } \\
(\mathrm{mg} / \mathrm{dl})\end{array}$ & $1.03+0.17$ & $1.91+0.25$ & $4.76+2.64$ & $<0.001^{* *}$ & $<0.001^{* *}$ & $<0.001^{* *}$ \\
\hline $\begin{array}{l}\text { Total cholesterol } \\
(\mathrm{mg} / \mathrm{dl})\end{array}$ & $130.25+23.32$ & $171.07+42.97$ & $162.18+49.00$ & $<0.001^{* *}$ & $0.004^{*}$ & 0.221 \\
\hline $\begin{array}{l}\text { Serum triglyceride } \\
(\mathrm{mg} / \mathrm{dl})\end{array}$ & $99.45+28.28$ & $142.8+62.14$ & $148.32+71.30$ & $0.004^{*}$ & $0.003^{*}$ & 0.601 \\
\hline HDL $(\mathrm{mg} / \mathrm{dl})$ & $61.70+11.68$ & $58.53+15.75$ & $49.63+16.50$ & 0.415 & $0.002^{*}$ & $<0.001^{* *}$ \\
\hline $\mathrm{LDL}(\mathrm{mg} / \mathrm{dl})$ & $76.70+16.24$ & $101.37+29.93$ & $92.56+31.39$ & $<0.001^{* *}$ & $0.027^{*}$ & 0.063 \\
\hline
\end{tabular}

Values are expressed as Mean+SD. Significant rise in total cholesterol, triglycerides, LDL and fall in HDL in group B and group C comparing to group A. There is an extremely significant fall in HDL when comparing group B and group C.

Table 5 shows there is a significant rise in total cholesterol, triglycerides, LDL and fall in HDL in group B and group C comparing to control (group A) with decreasing e-GFR. There is an extremely significant fall in HDL $\left(\mathrm{p}<0.001^{* *}\right)$ when comparing group $\mathrm{B}$ and group $\mathrm{C}$ signifies increasing dyslipidemia with decreasing e-GFR, with increasing severity of CKD.

\section{DISCUSSION}

The current study was a cross-sectional study done to find out the derangement in lipid profile found in different stages of CKD, to find out its relationship with the severity of the disease in this part of the world.

In our study group, $64.50 \%$ of patients were male and $35.50 \%$ of patients were female with M: F of 1.8:1. In CKD Registry of India 2007 [21], the male cases were $68.9 \%$ and female cases were $31.1 \%$. Similar results to the current study were seen in studies by Abraham et al. [22] and Ganta et al. [23]. Mean age of cases was $56.66 \pm 12.22$ y and control was $41.05 \pm 17.75 \mathrm{y}$. This was similar to that of CKD Registry of India 2007 [21] where the mean age of cases was $48.3 \pm 16.6 \mathrm{y}$ and in the studies by Patel and Sirajwala et al. [24] and by Mohanty et al. [25].

As depicted in fig. 1, 46 and $60 \mathrm{y}$ of age group consists the highest percentage of the study population with $45.04 \%$ of the patients followed by 61 and 75 y of age group with $27.86 \%$ of the patients. $66.41 \%$ being below 60 y age group, which is a worrisome factor. It is bothering that all the cases in 15-30 y age group are severe CKD (stage 4 and 5). In CKD Registry of India 2007 [21], 71.2\% of the cases belonged to age group of 19-60 y.

The mean e-GFR was found to be $20.37 \pm 11.34$ in cases; a significant fall in e-GFR in CKD cases. The mean eGFR of study by Sumanth and 
Shobharani [26] was $22.22 \pm 8.70$ showing results similar to our study. On basis of severity grades, $44.66 \%$ of cases were in G4 grade and $34.35 \%$ of cases were in G5 grade as shown in fig. $1.79 .01 \%$ of the study population was in G4 and G5 stage with e-GFR $<30 \mathrm{ml} / \mathrm{min}$. In CKD Registry India 2007 [21], 74.3\% cases were in G4 and G5 stage. In a study by Ganta et al. [23] $82.85 \%$ cases were in G4 and G5 stage. These findings were similar to those in our study.

$32.82 \%$ CKD cases had hypertension in our present study. Combined diabetes mellitus and hypertension was found to be associated with $43 \%$ of cases of CKD in Mahishale et al. study [27].

$30.18 \%$ male and $37.63 \%$ female CKD cases had hypertension. The association between HTN and gender distribution is not statistically significant $(\mathrm{p}=0.271)$ [table 1].

$68.70 \%$ (180) of the patients in our study population had dyslipidemia with any one of the parameters. The prevalence of dyslipidemia among CKD patients with relation to the severity is statistically significant $\left(\mathrm{p}=0.033^{*}\right.$ ) (table 2). The prevalence of dyslipidemia in non-diabetic CKD as calculated in Ganta et al. [23] is found to be $65.71 \%$ in patients with CKD without any prior history of diabetes.

In our study, we had $19.61 \%$ of CKD cases with hypercholesterolemia. Ganta et al. [23], Saroj K et al. [28] and Anderson et al. [29] found 22.86\%, 34.4\%, 20\% of CKD cases with hypercholesterolemia in their study respectively. In our study population, there is a marked elevation of triglycerides in $37.40 \%$ of patients. A study by Saroj K et al. reported a prevalence of $36.6 \%$ of hypertriglyceridemia in CKD [28]. $21.37 \%$ of the study group was having HDL level below $40 \mathrm{mg} / \mathrm{dl}$. Similarly, Ganta et al. [23] study found a decreased level of HDL in 21.43\% of cases with CKD. 11.07\% of our study group population had an increased level of LDL. Poudel et al. reported an undesirable level of LDL in $38.03 \%$ of cases [30] The LDL cholesterol is abnormal in only $12.86 \%$ of the study population in Ganta et al. [23] study, which is very similar to our study.

As shown in table 3, negative Pearson's correlation coefficient value indicates the level of triglyceride increase with the decline of GFR and positive Pearson's correlation coefficient value indicates the level of HDL decrease with the decline of GFR; which was statistically significant $\left(\mathrm{r}=0.1962, \mathrm{p}=0.001^{* *}\right)$. Paul and Kurien et al. [31] in separate studies showed a significant inverse correlation between triglyceride and e-GFR and significant positive correlation between high-density lipoprotein and e-GFR $(\mathrm{p}=<0.001)$. Kumari et al. [32] found a negative correlation between serum HDL-C level and serum creatinine levels, which were statistically significant. Muntner et al. have shown that people with low HDL values and high TG values have an increased risk of renal function alteration [33].

Table 4 shows the comparison between lipid profiles of cases and controls showed significant difference between total cholesterol $\left(\mathrm{p}=0.002^{*}\right)$, triglyceride $\left(\mathrm{p}=0.002^{*}\right), \operatorname{HDL}\left(\mathrm{p}=0.008^{*}\right), \operatorname{LDL}(\mathrm{p}=$ $\left.0.013^{*}\right)$. On comparing various parameters between cases and controls, there is a significant rise in blood Urea $\left(\mathrm{p}<0.001^{* *}\right)$ and serum Creatinine $\left(\mathrm{p}<0.001^{* *}\right)$. Mohanty et al. study also showed similar significant statistical association of total cholesterol ( $p=$ $0.001)$, triglyceride $(\mathrm{p}=0.001)$, HDL $(\mathrm{p}=0.000)$, LDL $(\mathrm{p}=0.000)$ between control and cases [25]. Kumari et al. study also found similar results to our study [32].

Table 5 shows there is a significant rise in total cholesterol, triglycerides, LDL and fall in HDL in moderate CKD (group B) and severe CKD (group C) comparing to control (group A) with decreasing e-GFR. There is an extremely significant fall in HDL $\left(\mathrm{p}<0.001^{* *}\right)$; comparing moderate CKD (group B) to severe CKD (group C); signifies increasing dyslipidemia with decreasing e-GFR with increasing severity of CKD.

These findings indicate a rise in serum total cholesterol, triglycerides, low-density lipoproteins and a fall in high-density lipoproteins in CKD with a fall in e-GFR. Similar changes in lipid profiles were seen by Ganta V et al. [23], Patel and Sirajwala [24], Mohanty et al. [25] and Machnur et al. [34].

\section{LIMITATION}

A more widespread study including large number of patients and for longer duration; with appropriate clinical trial is required to attain a firm conclusion. Assessment of predialysis and post dialysis lipid profile parameters in the same CKD patient and follow up lipid profile evaluation after repeated hemodialysis will provide more consistent information on the effect of hemodialysis on lipid profile parameters in CKD patients.

\section{CONCLUSION}

The results of the present study provide valuable information and an association between lipid abnormalities and CKD patients, concluding that the prevalence of dyslipidemia in non-diabetic CKD is high enough to pose a major health problem and this problem of dyslipidemia increases with the severity of CKD. A high degree of abnormality is found in HDL with disease progression, which is statistically significant. This study confirms the presence of atherogenic lipid profile in CKD patients, which can lead to renal disease progression; and increased morbidity and mortality due to additional CVD risks. Therefore, maintenance of desired lipid parameters either through diet or early initiation of lipid-lowering drugs can be helpful in decreasing the risk of cardiovascular complications in CKD patients.

\section{ACKNOWLEDGMENT}

Authors would like to thank Dr. Partha S. Mohanty, Dr. Arunima Pattanaik, Dr. Sambit Parida, Dr. Soumyasmruti Parida, Nibedita Mantry, Swarnalata Samal, Saraswati Sahoo, Rubina Soren, Mamata Nayak, Suchismita Patra, staffs of Department of Medicine, PRM Medical College, Baripada, Odisha, India for their cooperation.

\section{FUNDING}

Nil

\section{AUTHORS CONTRIBUTIONS}

Dr. Bibhu Prasad Behera designed the study, collected the data involved in interpreting the data, performed all statistical analysis and writing the manuscript.

\section{CONFLICT OF INTERESTS}

\section{Declared none}

\section{REFERENCES}

1. Bargman JM, Skorecki K. Chronic kidney disease in Harrison's principles of internal medicine. Vol 2. 20th edn. McGraw-Hill Publication 2018;335:2111-21.

2. Kaptein EM, Quion Verde H, Chooljian CJ, Tang WW, Friedman PE, Rodriquez HJ, et al. The thyroid in end stage renal disease. Medicine (Baltimore) 1988;67:187-97.

3. Veerappan I, Abraham G. Chronic kidney disease: current status, challenges and management in India. In: Medicine Update. Mumbai: Association of Physicians of India; 2013. p. 593-7.

4. Kher V. End-stage renal disease in developing countries. Kidney Int 2002;62:350-62.

5. Jha V, Garcia Garcia G, Iseki K. Chronic kidney disease: global dimension and perspectives. Lancet 2013;382:260-72.

6. CKD registry of India: Indian Society of Nephrology. Available from; http://www.ckdri.org [Last accessed on 20 Jan 2020]

7. Agarwal SK, Dash SC, Irshad M. Prevalence of chronic renal failure in adults in Delhi, India. Nephrol Dial Transplant 2005;20:1638-42.

8. Babua C, Kalyesubula R, Okello E, Kakande B, Sebatta E, Mungoma $\mathrm{M}$, et al. Cardiovascular risk factors among patients with chronic kidney disease attending a tertiary hospital in Uganda. Cardiovascular J Afr 2015;26:177-80.

9. Ata Sedik Elsayed, Azab Elsayed Azab. Correlation between chronic kidney diseases and hematological data in sabratha hospital in Libya. Asian J Pharm Clin Res 2017;10:291-6.

10. Thomas R, Kanso A, Sedor JR. Chronic kidney disease and its complications. Prim Care 2008;35:329-44. 
11. Tsimihodimos V, Mitrogianni Z, Elisaf M. Dyslipidemia associated with chronic kidney disease. Open Cardiovascular Med J 2011;5:41-8.

12. Tudor MN, Mitrea A, Popa SG. Apolipo proteins: good markers for cardiovascular risk in patients with CKD and dyslipidemia. Romanian J Diabetes Nutr Metab Diseases 2014;21:185-91.

13. Ulosoy S, Ozkan G. Lipid abnormalities in haemodialysis patients. Haemodialysis 2013;6:101-25.

14. Nelson RH. Hyperlipidemia as a risk factor for cardiovascular disease. Primary Care: Clin Office Practice 2013;40:195-211.

15. Miller M. Dyslipidemia and cardiovascular risk: the importance of early prevention. QJM 2009;102:657-67.

16. Trevisan R. Lipids and renal disease.J Am Soc Nephrol 2006;17(4, Suppl 2):S145-7.

17. Chen SC, Hung CC, Kuo MC, Lee JJ, Chiu YW, et al. Association of dyslipidemia with renal outcomes in chronic kidney disease. PLoS One 2013;8:e55643.

18. Issa V, Andrade L, Bocchi E. Current strategies for preventing renal dysfunction in patients with heart failure: a heart failure stage approach. Clinics 2013;68:401-9.

19. Tsimihodimos V. Dyslipidemia associated with chronic kidney disease. Open Cardiovascular Med J 2011;5:41-8.

20. Definition and classification of chronic kidney disease: a position statement from kidney disease: improving global outcomes (KDIGO). Kidney Int 2005;67:2089-100.

21. Dash ASC, Rana DS, Sharma RK. 2nd annual report CKD registry of India, Indian Society of Nephrology; 2007.

22. Abraham G, Sundaram V, Sundaram V. C-reactive protein, valuable predictive marker in chronic kidney disease. Saudi J Kidney Dis Transpl 2009;20:811-5.

23. Ganta V, Yalamanchi RP, Mahanta KC. A study of lipid profile in non-diabetic chronic kidney disease. Int J Adv Med 2016;3:965-70.
24. Patel L, Sirajwala H. Serum apolipoprotein a-1, apolipoprotein $\mathrm{b}$ and apo B/Apo A-1 ratio as cardiovascular risk indicators in patients of chronic renal failure. Int J Biomed Adv Res 2014;5:234-6

25. Mohanty R, Acharya R, Thatoi PK. Dyslipidaemia in CKD patients and its correlation with the severity of renal dysfunction. J Evolution Med Dent Sci 2018;7:1323-7.

26. Sumanth BK, Shobharani B. Comparative study of Hscrp in chronic kidney disease. IOSR J Pharm 2015;5:8-12.

27. Mahishale GS, Allolli D, Patil A, Basavaraj PG, Shetagar S, Talikoti S. Cardiovascular profile of patients with chronic kidney disease. Int J Res Med Sci 2019;7:2582-7.

28. Saroj K, Rajendra KC, Sharad G. Thyroid dysfunction and dyslipidemia in chronic kidney disease patients. Endocr Disord 2015;15:65.

29. Anderson SG, Diego L, Brenner BM. Renal and systemic manifestations and glomerular disease. 4th ed. Philadelphia: $\mathrm{W}$ B. Saunders Company; 1991

30. Poudel B, Yadav BK, Jha B, Raut KB. Dyslipidemia in chronic kidney disease in Nepalese population. Mymensingh Med J 2013;22:157-63.

31. Paul JK, Kurien SV. Study of lipid profile in chronic kidney disease patients of non-diabetic aetiology and its relation to serum calcium. JMSCR 2017;5:28284-90.

32. Kumari KR, Srinivas B. Study of lipid profile in patients with chronic kidney disease on conservative management and hemodialysis. Int J Sci Stud 2018;6:108-13

33. Muntner P, Coresh J, Smith JC, Ekfeldt J, Klag MJ. Plasma lipids and risk of developing renal dysfunction: the atherosclerosis risk in communities. Kidney Int 2000;58:293-301.

34. Machnur B, Chandrashekar. Lipid abnormality in chronic kidney disease: descriptive study. Int J Med Res 2016;1:19-21. 